\title{
Promoting Cooperative Learning in the Classroom: Comparing Explicit and Implicit Training Techniques
}

\author{
Susan Mitchell \\ Vera E. Woloshyn \\ Anne E. Elliott
}

\begin{abstract}
In this study, we investigated whether providing $4^{\text {th }}$ and $5^{\text {th }}$-grade students with explicit instruction in prerequisite cooperative-learning skills and techniques would enhance their academic performance and promote in them positive attitudes towards cooperative learning. Overall, students who received explicit training outperformed their peers on both the unit project and test and presented more favourable attitudes towards cooperative learning. The findings of this study support the use of explicitly instructing students about the components of cooperative learning prior to engaging in collaborative activities. Implications for teacher-education are discussed.
\end{abstract}

Three decades of research document that instructing students to use cooperative learning techniques improves both their academic and social performances (Antil, Jenkins, Wayne, \& Vaasy, 1998; Blumfield, Marx, Soloway, \& Krajcik, 1996; Kahl \& Woloshyn, 1994; Shachar \& Sharon, 1994; Sharon, 1994; Slavin, 1990, 1995). It is also widely accepted that cooperative learning involves more than simply placing students into groups (Kagan, 1990; Natasi \& Clements, 1991; Thousand, Villa, \& Nevin, 1994). Specifically, Johnson and Johnson (1990, 1991, 1994) have long argued that students must be taught five critical skills or components in order for them to collaborate effectively. These components include: (a) Positive interdependence where an individual student's success is dependent on the success of his or her group; (b) Positive face-toface interactions where students develop a sense of sharing, understanding, and accumulated group knowledge; (c) Individual accountability where each student is required to demonstrate his or her own learning; (d) Interpersonal and smallgroup skills including effective communication, conflict-resolution, and

Vera E. Woloshyn and Anne E. Elliott are Associate Professors of Education at Brock University, where they conduct research on explicit strategy instruction and children's social development. Susan Mitchell is an elementary teacher and recent graduate student in Education. 
decision-making; and (e) Critical reflection on academic and social processes.

The question arises as to how educators might best teach students these somewhat ambiguous skills. It is well documented that students best learn the strategic processes associated with reading and writing best when instruction is explicit (e.g., Butyniec-Thomas \& Woloshyn, 1997; Gallagher \& Woloshyn, 1999; Harris \& Graham, 1992; Pressley et al., 1992; Woloshyn \& Elliott, 1998). Briefly, such instruction requires teachers to model critical learning strategies or processes and to provide students with information about the parameters associated with their use. Explicit instruction also includes providing students with multiple opportunities to practice using those critical strategies or processes. By reflecting on the quality of their work before and after using strategies, students are encouraged to "discover" that strategic approaches are superior to non-strategic ones. Explicit-strategy instructors often share stories of their own learning experiences, highlighting instances where their successes could be attributed to the use of strategic processes. Finally, explicit instruction requires educators to continually prompt their students to transfer and generalize the use of relevant learning processes across the curriculum.

A review of the cooperative learning literature, as well as the supporting teacher-materials and resources, suggests that many critical skills associated with cooperative learning processes may not always be presented to students in an explicit fashion (Battistich, Solomon, \& Delucchi, 1993; Johnson \& Johnson, 1994; Kagan, 1990b; Slavin, 1994; 1995). Rather, information about these learning processes seems to be provided at an implicit or incidental level. For instance, prerequisite skills (positive interdependence, positive faceto-face interactions, individual accountability, interpersonal and small-group skills, and critical reflection) are not labelled or taught consciously as part of the planned curriculum and students are usually not provided with examples of "how," "when," and "where" to use them. Consequently, students may not fully acquire these skills or readily realize that the cooperative processes they have completed for one task can be transferred to similar learning situations. Such situations can prove frustrating to students and to teachers alike and may impede the widespread use of cooperative learning.

Research also supports the importance of providing students with a "structure" or "format" for discussion while working cooperatively. For instance, Kahl and Woloshyn (1994) documented that students who received instruction in both question answering and cooperative learning prior to completing an academic activity demonstrated superior learning to students who received only question-answering or cooperative-learning instructions.

Similarly, research carried out by Meloth and Deering $(1992,1994)$ and Berg (1993) confirm that students' cooperative learning experiences can be enhanced 
when they are provided with specific training with respect to how to engage in effective cognitive processes.

The primary purpose of this study was to investigate whether providing students with explicit instruction in the "socially-based" prerequisite skills or components of cooperative learning would facilitate their academic performance and promote more positive attitudes towards cooperative learning. This approach is in contrast to the more common form of implicit instruction where students are focused on completing the learning task rather than focused on the collaborative process.

\section{Methods}

\section{Participants}

Twenty-four grade-4 students and 24 grade- 5 students ( 29 males, 19 females, $M$ age $=9$ years 7 months) participated in this study. All students were native English speakers with parents of lower- to middle-income socio-economic status. While all students had completed group activities and had been provided with opportunities to work with their peers in the past, none had been provided with formal instruction in cooperative learning. Half of the students in each grade were assigned randomly to either the explicit or implicit cooperative-learning training conditions. Students were then assigned to heterogeneous groups within their grade levels. These groups consisted of four students each for a total of six groups in each condition. Students' classroom teachers confirmed that the groupings contained children of mixed academic abilities. All training and instructional sessions were delivered by the first author, who has over a decade of experience teaching in the elementary grades.

\section{Cooperative Learning Training Conditions}

Explicit-training cooperative learning condition. Students in the explicit condition received a total of ten 50-minute cooperative- learning training sessions. Specifically, seven of these lessons involved explicit instruction and practice of a prerequisite cooperative learning skill or component (e.g., learning styles, working roles, social roles, reflection). As part of these lessons, students were asked to identify the social skills that people need in order to work together well (e.g., listening, complementing, encouraging). During each lesson, the primary researcher modelled these critical skills and instructed students to demonstrate what they "looked like" and "sounded like." As part of these lessons, students also discussed the benefits 
associated with cooperative learning, how it differed from other formats of learning, and when it was an appropriate learning tool. For example, students were provided information about individual, competitive, and cooperative learning styles and discussed why the latter was a preferred method for learning. They identified that life in a global world was interdependent and problems such as pollution could only be solved if people worked together. They also identified instances where they had learned from and taught family members and friends. The primary researcher shared instances from her life when she worked cooperatively with others and contrasted the benefits associated with those working experiences to other instances when she worked alone.

Students also participated in short "role-plays" demonstrating behaviours associated with each learning style or approach. The primary researcher modelled language associated with each approach (e.g., "me instead of you" for competitive; "me alone" for individual; "we as well as me" for cooperative), with students encouraged to adopt cooperative terms (e.g., "I can attain my goal only if you attain yours"; "We share materials and ideas"; "We care about the success and effort of our group"). Students also spent considerable time exploring the concepts of accountability, motivation, and group responsibility. To this end, the primary researcher modelled what appropriate levels of concern, interest, nurturing, and constructive feedback might look like in a group, with students, in turn, participating in relevant role plays. Throughout these series of lessons, students created a "team" identity and practiced preparing themselves to engage in a group activity in an expedient fashion (e.g., gathering and sharing materials, negotiating, and assuming relevant roles).

Students also participated in role-plays and reflective discussions of past experiences in order to develop skills in academic and social roles that they would need to assume when working cooperatively. For instance, the primary researcher modelled such roles as "recorder", "summarizer", "encourager", and "monitor" and provided opportunities for students to assume each position. Similarly, the researcher modelled and provided opportunities for the students to practice such communication techniques as "think-pair-share" (i.e., students reflect on a topic individually, share their thoughts with a partner, participate in whole-group discussion), "round robins" (i.e., individual students formulate a written response to a printed message and circulate their response to another member who reads and adds his or her commentary and ideas), and "corners" (i.e., unique perspectives on a given topic are represented in each corner of a square, with students assuming the position of the corner they occupy).

For the final three lessons in the series, students participated in "teambuilding" activities where they were required to complete an interest inventory/ 
interview; build a plasticine boat that would hold ten marbles, and create and present an original product. During each session, students reflected on and completed an evaluation form monitoring their contributions to the team, their ability to communicate effectively with each other, and their general enjoyment of the group process. Group members were also encouraged to reflect on alternative methods for solving the identified problems.

Implicit- training cooperative learning condition. Students in the implicit training condition also participated in ten 50-minute cooperativelearning training sessions. During the first session, the primary researcher provided students with information about the three approaches to learning (individual, competitive, and cooperative) and informed them that the latter was associated with increased academic and social performance. Students briefly discussed the importance of working collaboratively and practiced basic communication skills as listening, taking turns, and staying on task. Students also practiced completing an evaluation form for the purposes of reflecting on group processes.

The remaining sessions consisted of "team-building" activities designed to establish trust and rapport among students (e.g., interviewing, team discovery, desert-island decision making, boat construction, creating and presenting an original product). These activities are consistent with those typically used in classrooms when preparing students to work cooperatively (e.g., Sharon, 1994). Students in this condition did not explicitly discuss the advantages associated with cooperative learning or the parameters associated with its use. Furthermore, the primary researcher did not model or explicitly label cooperative-learning skills or components nor were students provided with extended opportunities to practice them.

\section{Famous Artists Curriculum Unit}

After participating in either the explicit or implicit cooperative-learning training sessions, all students completed a famous-artists unit. The unit extended over eight days, with each lesson lasting 60 minutes. During each lesson, the students worked in the same cooperative-learning groups that they formed during the training sessions to study the "works and times" of six famous artists including Rembrandt, Monet, Van Gough, Da Vinci, Picasso, and Gauguin. The famous-artists unit was part of students' regular school curriculum and represented their first formal experience studying these artists.

On the first day, students were provided with information about the guidelines and requirements of the famous-artists unit. Specifically, the primary 
researcher described each requirement and recorded this information on chart paper that was displayed for the duration of the unit. Students were also told that they would complete a summative test assessing their knowledge of each artist.

For each subsequent class session, students were provided with a onepage information sheet outlining critical information about each artist

(Appendix A). Students were instructed to use this information as part of their unit project. Additional texts and materials about each artist were also available in the classroom. Each day, students were instructed to complete five activities that cumulatively would form the basis of the famous-artists unit project.

Project requirements included having students describe three-to-five facts about each artist's work, family life, and cultural background. Students were also required to identify and describe three paintings associated with each artist, as well as provide three "interesting" facts about them. Finally, students were instructed to illustrate an important aspect of each painter's life. The researcher collected students' work at the end of each session.

Famous-artists unit project. Each cooperative group was provided one additional class session to complete its famous-artists project. Students were encouraged to present information in creative/innovative formats such as webs, charts, mind maps and to include a title page and table of contents. Two educators, with over 15 years of teaching experience each, assessed the students' projects across six criteria: answer completion, answer elaboration, creativity, organization, illustrations, and appearance. Briefly, the "completeness" score reflected students' ability to complete all the project requirements, "elaboration" measured whether students had gone beyond the project requirements, "creativity" captured whether students used a variety of formats to present information, "organization" assessed the order of presentation and flow of information, "illustrations" included the use of titles and labels, and "appearance" provided an overall measure of the neatness and professional presentation of the project. For each criterion, students were awarded a score out of five. For instance, students were awarded a score of five if their illustrations were coloured, clearly labelled, and included extra details and efforts. Contrarily, students received a score of one if their illustrations that were not coloured, did not contain accurate or complete labels, and contained no additional details. Students' projects that had some colour, details, and met the minimal requirement of one illustration per artist received a score of three. Each project was awarded a total score out of 30. The teachers were unaware of students' assignment to the experimental conditions, with all scoring discrepancies being resolved through discussion. 
Promoting Cooperative Learning in the Classroom

\section{Attitudinal Questionnaire}

The day after completing the famous-artists unit project, students completed a 20-item questionnaire assessing their attitudes and beliefs about cooperative learning. Students responded to each item using a 5-item Likert scale where "1" indicated that they strongly disagreed and " 5 " that they strongly agreed. The students were instructed to respond as honestly as possible and were assured that their responses would in no way reflect their project grades. Instead they were told that the questionnaire would provide the researchers with valuable information about the usefulness of cooperative learning when working with grade-4 and grade- 5 students. The questionnaire consisted of items assessing students' perceptions about their ability to work cooperatively (e.g., I know how to work in a cooperative group; I stay on task when working with others; I accept everyone's opinion in my group), benefits associated with collaborative endeavours (e.g., I am better at solving conflicts now; I learn well when working collaboratively; Knowing how to work cooperatively will help me when I am older), and overall enjoyment of the cooperative process (e.g., I enjoy sharing my ideas with my group; Cooperative learning is fun; I wish we could work in cooperative groups more often). Students also responded to five, open-ended questions (e.g., I have learned the following about cooperative learning... about others... about myself, The best/worst aspect of cooperative learning is....). There was no discussion while students completed the questionnaire, with the survey taking approximately 20 minutes to complete.

\section{Academic Test}

Students also completed a 25-item famous-artists test consisting of 12 matching phrases, 10 true-false statements and 3 short-answer questions. Specifically, the matching-phrases section required students to match facts or famous paintings to artists (e.g., __ _ cut off part of his ear; __ painted himself in bright clothes and jewels; ___ painted "Women in the Garden"; ___ painted "Sunflowers"). Similarly, students were instructed to respond "True" or "False" to other factual statements about each artist during the second section of the test (e.g., Van Gogh was a preacher before he became a painter; Da Vinci was one of the first artists to paint the mother of Jesus smiling and playing with her baby). The open-ended questions required students to list three artistic styles used by these painters (e.g., brush strokes to provide a sense of movement).

The students were instructed to answer each item and to provide their best guess when they were uncertain about the correct answer. Students were given 60 minutes to complete the test. The primary researcher and another 
educator at the school graded the students' tests, with one point being awarded to each correct response for a total score out of 25 .

\section{Results}

For each dependent measure, a one-way ANOVA was used to analyze students' performance scores with the Tukey-Kramer HSD test for posthoc analyses. When nonparametric statistics were used to analyze students' attitudinal responses, a similar pattern of findings was obtained. In order to establish consistency across the reporting of the dependent measures and because ANOVA procedures are robust to violations of variance (Kirk 1982), only parametric statistics are reported here. Students' mean and standard deviation scores for the famous-artists project, attitudinal questionnaire, and famousartists academic test are listed in Tables 1,2, and 3 respectively as a function of scoring criteria/item type and experimental condition.

\section{Famous-Artists Unit Project}

The total project scores for students in the explicit-training condition were significantly greater than the project scores for students in the implicit-training condition, $F(1,45)=67.05, q=6.00, p<.05$. Specifically, students in the explicit-training condition outscored their peers on five of the six scoring criteria including, answer completeness $F(1,45)=53.03$, answer elaboration $F(1,45)=41.86$, organization $F(1,45)=66.74$, illustrations $F(1,45)=40.76$, and appearance $F(1,45)=52.06$, smallest $q=4.40$, all $p$ s $<.05$. Students scores did not differ on the creativity measure, $F(1,45)=1.69, p>0.5$.

\section{Attitudinal Questionnaire}

Overall, students assigned to the explicit-training condition expressed more favourable attitudes towards cooperative learning than did students in the implicittraining condition, $F(1,45)=5.12, q=1.60, p<.05$. Descriptive analysis of the individual questionnaire items revealed that students in the explicit-training condition consistently provided greater endorsements across all statements in favour of cooperative learning. Furthermore, students in the explicit condition provided statistically greater endorsements for such statements as, "I learn well when working in cooperative groups" $F(1,45)=20.96, q=3.23$, "I stay on task during group work" $F(1,45)=12.12, q=2.50$, and "I accept the contributions of every member of my group" $F(1,45)=4.52, q=1.52$, all $p \mathrm{~s}<.05$. 
Table 1

Famous-Artists Project Means and Standard Deviations as a Function of Scoring Criteria and Experimental Condition

\begin{tabular}{|c|c|c|}
\hline Scoring C riteria & $\begin{array}{c}\text { Explicit-Training } \\
\text { Cooperative Leaming } \\
\text { Condition }\end{array}$ & $\begin{array}{c}\text { Implicit-Training } \\
\text { Cooperative Leaming } \\
\text { Condition }\end{array}$ \\
\hline \multicolumn{3}{|l|}{ A nsw er $C$ ompleteness } \\
\hline M & 4.56 & 3.07 \\
\hline SD & 0.62 & 0.8 \\
\hline \multicolumn{3}{|l|}{ A nsw er E bboration } \\
\hline M & 3.76 & 1.78 \\
\hline SD & 0.89 & 1.17 \\
\hline \multicolumn{3}{|l|}{ C reativity } \\
\hline M & 2.71 & 223 \\
\hline SD & 1.45 & 1.08 \\
\hline \multicolumn{3}{|l|}{ O rganization } \\
\hline M & 4.14 & 2.13 \\
\hline SD & 0.56 & 1.04 \\
\hline \multicolumn{3}{|l|}{ Illustrations } \\
\hline M & 3.37 & 2.65 \\
\hline $\mathrm{SD}$ & 0.43 & 0.33 \\
\hline \multicolumn{3}{|l|}{ A ppearance } \\
\hline M & 3.67 & 2.35 \\
\hline SD & 0.55 & 0.73 \\
\hline \multicolumn{3}{|l|}{ TotalScore } \\
\hline M & 22.11 & 14.02 \\
\hline $\mathrm{SD}$ & 3.1 & 3.48 \\
\hline
\end{tabular}


Two independent reviewers scored students' responses on the openended questions (i.e., What have I learned about cooperative learning? What have I learned about others? What have I learned about myself? and What is the best/worse aspect of cooperative learning?). Specifically, students' responses were scored as either being supportive/positive of cooperative learning or as being unsupportive/negative of cooperative learning. Agreement between the two reviewers was high (97\%), with differences being resolved through discussion.

When asked what they had learned about others, students in the explicit-training condition provided more positive responses than their peers, $F(1,45)=3.94, q=1.38, p<.05$. Examples of positive responses included, "different people have different ideas", "everyone has different feelings and different talents," and "they help you when you are having trouble."

Equally as positive, students in the explicit-training condition provided fewer negative statements across all five open-ended questions than did students in the implicit-training condition $F(1,45)=3.24, q=1.99, F(1,45)=3.14$, $q=1.30$, and $F(1,45)=6.11, q=1.78$, all $p$ s $<.05$. Examples of negative statements provided by students in the implicit condition included, "nothing", "some people don't listen and just talk to others", "people are mean", and "it is hard to work together."

\section{Academic Test}

In general, students performed moderately well on the famous-artists academic test, with students in the explicit-training condition outperforming their peers across each measure of the test. Specifically, students in the explicit-instruction condition obtained greater total scores on the famous-artists unit test than did students in the implicit condition, $F(1,45)=16.41, q=4.05, p<.05$. Separate analyses were completed for each component of the unit test. Explicitly-trained students' matching scores were significantly greater than those of implicitlytrained students, $F(1,45)=35.76, q=5.98, p<.05$. However, students scores on the true/false and fill-in-the-blank portions of the test did not differ as a function of experimental condition, $F(1,45)<45, p>.05$. 
Table 2

Cooperative-Learning Attitudinal Questionnaire Means and Standard Deviations as a Function of Item Type and Experimental Condition

\begin{tabular}{|c|c|c|}
\hline Item Type & $\begin{array}{l}\text { Explicit-Training } \\
\text { Cooperative } \\
\text { Leaming Condition }\end{array}$ & $\begin{array}{c}\text { Im plicit-Training } \\
\text { C ooperative } \\
\text { Leaming C ondition }\end{array}$ \\
\hline 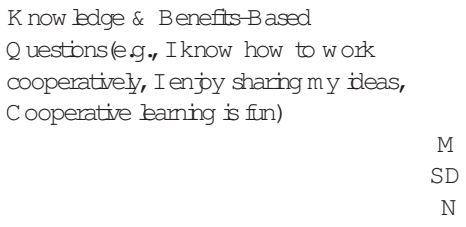 & $\begin{array}{c}44.68 \\
6.99 \\
10\end{array}$ & $\begin{array}{c}41.35 \\
10.70 \\
10\end{array}$ \\
\hline $\begin{array}{l}\text { SocialB ased } Q \text { uestions (e.g., I accept every } \\
\text { m em ber ofm y group, I am not em banrassed } \\
\text { to share ideas, I respond constructively to } \\
\text { others' ileas) } \\
\\
\mathrm{M} \\
\mathrm{SD} \\
\mathrm{N}\end{array}$ & $\begin{array}{c}37.49 \\
9.07 \\
10\end{array}$ & $\begin{array}{c}35.82 \\
11.38 \\
10\end{array}$ \\
\hline Totalscore & $\begin{array}{c}82.17 \\
3.16 \\
20\end{array}$ & $\begin{array}{c}77.17 \\
9.67 \\
20\end{array}$ \\
\hline
\end{tabular}

Table 3

Famous-Artists Academic Test Means and Standard Deviations as a Function of Item Type and Experimental Condition

\begin{tabular}{|r|c|c|}
\hline Test Type & $\begin{array}{c}\text { Explicit-Training } \\
\text { Cooperative } \\
\text { Leaming } \\
\text { Condition }\end{array}$ & $\begin{array}{c}\text { Im plicit-Training } \\
\text { Cooperative } \\
\text { Leaming } \\
\text { Condition }\end{array}$ \\
\hline M atching \\
SD
\end{tabular}




\section{Conclusions and Discussion}

The varying degrees and effectiveness of instructional approaches and teaching techniques continue to be a central topic among researchers and educators (Elliott \& Woloshyn, 1996; Stevens \& Slavin, 1995). Within the past two decades, there has been an upsurge in the use of cooperative-learning practices in the classroom (Antil, et al., 1998; O'Connor \& Jenkins, 1996). Many times, however, students only receive minimal instruction in socially-oriented collaborative concepts and techniques prior to engaging in cooperative activities. While even this "minimal" approach to cooperative learning has been associated with increased academic performance and enhanced social skills, the question arises whether these benefits might be even greater following explicit instruction in critical concepts associated with cooperative learning. Research has clearly documented that students learn best when provided with explicit instruction in such traditional areas as reading and writing (e.g., Butyniec-Thomas, \& Woloshyn, 1997; Gallagher\& Woloshyn, 1999; Harris \& Graham, 1992; Pressley, et al., 1992; Woloshyn \& Elliott, 1998). The results of this study suggest that this may also be the case for cooperative learning. Specifically, providing fourth- and fifth-grade students with explicit training promoted more positive attitudes towards cooperative learning and enhanced their academic performance more than providing them with implicit training.

Students assigned to the explicit-training condition participated in conversations that addressed the overall value of cooperative learning and the specific value of effective communication skills and inclusive practices. The literature suggests that when students participate in such conversations, their communication skills improve, as does the quality of their academic products and related learning. At the same time, social skills improve within the classroom, motivation appears stronger and acceptance and friendliness among peers increases (Ashman \& Gillies, 1997; Battistich, et al., 1993; Lazarowitz, Hertz-Lazarowitz, \& Barid, 1994; Slavin 1990; 1994). It was therefore not surprising that the students in the explicit condition expressed more favourable responses to working cooperatively and rated themselves as more tolerant and accepting of others than did their peers.

Students assigned to the explicit-training condition also demonstrated superior academic gains compared to their peers who received implicit training. This was especially true for test items that required students to recall more obscure information about each artist (i.e., matching task) and is consistent with the overall findings of previous research demonstrating that students' academic 
learning improves as a function of cooperative learning (Antil, et al., 1998; Battistich, et al., 1993; Johnson \& Johnson, 1994; Nastasi \& Clements, 1991; Shachar \& Sharon, 1994).

In this study, completion of the famous-artists project was the one task that most required students to work cooperatively. According to observational field notes kept by the primary researcher, students who received explicit instruction were less likely to engage in non-academic activities (e.g., looking for materials, leaving for the washroom, participating in unrelated conversations) and dysfunctional speech (e.g., criticizing others' ideas, complaining about the task, refusing to contribute) during the class sessions than were their peers. In this study, students in the explicit-training condition were provided with the opportunity to practice the very skills that would most readily contribute to their success on the famous-artist project.

Given the positive findings associated with explicit instruction of process skills related to cooperative learning, the question arises as to why educators do not more readily provide their students with information about these techniques in a direct fashion. That is, why do so few teachers teach explicitly? One simplistic answer is that explicit instruction is somewhat difficult to understand and, in its initial phases, time consuming to implement (Pressley, Goodchild, Fleet, Zajchowski \&Evans, 1989; Woloshyn, Elliott, \& Riordon, 1998). Furthermore, most teachers have not received such instruction as students, nor has such instruction usually been a part of their teacher education. Just as students need repeated instruction and practice in order to acquire effective learning techniques and strategies, teachers typically require extensive in-servicing and ongoing mentoring to become proficient explicit instructors (Duffy, 1993; Woloshyn, et al., 1998). Without such supports, even experienced teachers may be unsuccessful at implementing explicit instruction (El-Dinary \& Schuder, 1993). Thus, we strongly encourage those involved in the delivery and implementation of teacher education programs to include explicit instruction as part of teachers' professional development. In this context, beginning and aspiring teachers need to understand the differences between explicit and implicit instruction. Furthermore, teacher educators need to provide them with opportunities to engage and reflect upon this process as it relates to the teaching of critical skills including cooperative learning.

Undeniably, the processes of explicit instruction and cooperative learning require commitment from both teachers and students. First, teachers must devote personal time to learning how to provide explicit instruction as part of cooperative learning. Second, they must be prepared to devote substantial class time to this process in order to provide students with multiple opportunities to acquire repertoires of effective learning and study skills. We 
believe that ultimately the personal satisfaction and realization that they are providing students with the necessary skills to become capable, independent learners in the $21^{\text {st }}$ century will outweigh teachers' initial reservations about time and effort when teaching cooperative learning explicitly.

\section{Acknowledgements}

This research was partially supported by a grant to Vera Woloshyn from the Social Sciences and Research Council.

\section{References}

Antil, L.R., Jenkins, J.R., Wayne, S.K., \& Vadasy, P.F. (1998). Cooperative learning: Prevalence, conceptualisations and the relation between research and practice. American Educational Research Journal, 35, 419-454.

Ashman A.F., \& Gillies, R. M. (1997). Children's cooperative behavior and interactions in trained and untrained groups in regular classrooms. Journal of School Psychology, 35, 261-279.

Battistich, V., Solomon, D., \& Delucchi, K. (1993). Processes and student outcomes in cooperative learning groups. The Elementary School Journal, 94, 19-32.

Berg, K. (1993, April). Structured cooperative learning and achievement in high school mathematics class. Paper presented at the American Educational Research Association (AERA), Atlanta, GA.

Blumfield, P.C., Marx, R.W., Soloway, E., \& Krajcik, J.S. (1996). Learning with peers: From small group cooperation to collaborative communities. Educational Researcher, 25, 37-40.

Butyniec-Thomas, J., \& Woloshyn, V.E. (1997). The effects of explicit-strategy instruction and whole-language instruction on students' spelling ability. Journal of Experimental Education, 65, 293-302.

Duffy, G.G. (1993). Rethinking strategy instruction: Four teachers' development and their low achievers' understandings. Elementary School Journal, 93, 231-247.

El-Dinary, P., \& Schuder, T. (1993). Seven teachers' acceptance of transactional strategies instruction during their first year using it. Elementary School Journal, 94, 207-219. 
Elliott, A., \& Woloshyn, V.E. (1996). Using collaborative learning strategies in the classroom: Overcoming teacher resistance. The Canadian School Executive, 15, 3-9.

Gallagher, T., \& Woloshyn, V.E. (1999). Comparing explicit multiple-spelling strategy instruction with traditional language arts instruction in eighthgrade students. Brock Education, 8, 36-46.

Harris, K.R., \& Graham, S. (1992). Helping young writers master the craft: Strategy instruction and self-regulation in the writing process. Cambridge, MA: Brookline Books.

Johnson, D.W., \& Johnson, R.T. (1990). What is cooperative learning? In M. Brubacher, R. Payne, \& K. Rickett, (Eds), Perspectives for small group learning (pp. 68-80). Oakville, ON: Rubicon Publishing Inc.

Johnson, D.W., \& Johnson, R.T. (1991). Classroom instruction and cooperative learning. In H. Waxman, \& H. Walberg, (Eds), Effective teaching: Current research (pp. 277-294). Berkeley, CA: McCutchan Publishing Company.

Johnson, D.W., \& Johnson, R.T. (1994). Learning together and alone: Cooperative, competitive, and individualistic learning ( $4^{\text {th }} \mathrm{ed}$.). Boston: Allyn \& Bacon.

Kagan, S. (1990a). Cooperative learning for students limited language proficiency. In M. Brubacher, R. Payne, \& K. Rickett, (Eds), Perspectives for small group learning (pp. 202-223). Oakville, ON: Rubicon Publishing Inc.

Kagan, S. (1990b). The structural approach to cooperative learning. Educational Leadership, 47, 12-15.

Kahl, B., \& Woloshyn, V.E., (1994). Using elaborative interrogation in cooperative learning settings: One good strategy deserves another. Applied Cognitive Psychology, 8, 465-478.

Kirk, R. (1982). Experimental design (2 ${ }^{\text {nd }}$ Ed.). Belmont, CA: Brooks/Cole.

Lazarowitz, R., Hertz-Lazarowitz, R., \& Barid, J.H. (1994). Learning science in a cooperative setting: Academic achievement and affective outcomes. Journal of Research in Science Teaching, 31, 1121-1131.

Meloth, M. S., \& Deering, P. D. (1992). Effects of cooperative conditions on peer-group discussions, reading comprehension, and metacognition. Contemporary Educational Psychology, 17, 175-193.

Meloth, M.S., \& Deering, P. D. (1994). Task talk and task awareness under different cooperative learning conditions. American Educational Research Journal, 31, 138-165.

Nastasi, B., \& Clements, D. (1991). Research on cooperative learning: Implications for practice. School Psychology Review, 20, 110-131. 
O’Connor, R.E., \& Jenkins, J.R. (1996). Cooperative learning as an inclusion strategy: A closer look. Exceptionality, 6, 29-51.

Pressley, M., El-Dinary, P.B., Gaskins, I., Schuder, T., Bergman, J.L., Almasi, J., \& Brown, R. (1992). Beyond direct explanation: Transactional instruction of reading comprehension strategies. Elementary School Journal, 92, 513-555.

Pressley, M., Goodchild, F., Fleet, J., Zajchowski, R., \& Evans, E.D. (1989). The challenges of classroom strategy instruction. Elementary School Journal, 89, 301-342.

Shachar, H., \& Sharon, S. (1994). Talking, relating, and achieving: Effects of cooperative learning circles. Instructional Science, 19, 445-466.

Sharon, S. (1994). Handbook of cooperative learning methods. Connecticut: Greenwood Press.

Slavin, R. E. (1990). Cooperative learning: Theory, research and practice. New Jersey: Prentice-Hall, Inc.

Slavin, R.E. (1994). Collaborative learning: Theory, research and practice (2 $2^{\text {nd }}$ ed.). Boston, MA: Allyn \& Bacon.

Slavin, R. E. (1995). Cooperative learning. Boston: Allyn \& Bacon.

Stevens, R. J., \& Slavin, R.E. (1995). The cooperative elementary school: Effects on students' achievement, attitude and social relationships. American Educational Research Journal, 32, 321-351.

Thousand, J. S., Villa, R. A., \& Nevin, A. I. (1994). Creativity and collaborative learning. Baltimore: Paul H. Brooks Publishing Co.

Woloshyn, V. E., \& Elliott, A. (1998). Providing seventh-and eighth-grade students with reading and writing strategy instruction: Comparing explicit-strategy and implicit-strategy programs. The Reading Professor, 20, 59-79.

Woloshyn, V. E., Elliott, A., \& Riordon, M. (1998). Seven teachers' experiences using explicit strategy instruction in the classroom. Journal of Professional Studies, 5, 18-28. 
Promoting Cooperative Learning in the Classroom

\section{Appendix A}

\section{Claude Monet}

Claude Monet was born in Paris, France, in 1840. When he was young he moved to a town right by the sea where ships from all over the world would stop to pick up supplies. Monet's father owned a grocery store that sold supplies to the sailors and shipping companies. Monet did not do very well in school. He had a very good sense of humour and spent most of his time drawing funny pictures. Monet made money by selling these drawings and eventually tried painting.

Monet tried the idea of painting outdoors and he loved it. Many of Monet's paintings are of boats, oceans, ponds, and lakes. Monet even fixed up a boat as a floating studio. He sailed up and down rivers stopping to paint whatever he liked.

The Salon was a place in Paris where people came from all over the world to see famous artists' paintings. Monet entered his paintings often. Some were accepted and some were not. "Women in the Garden" was one of Monet's paintings that didn't make it into the Salon gallery. In this painting Monet used his favourite model, Camille, for all four women in the painting. Monet and Camille got married and had a son named Jean.

Monet helped invent an important style of painting called impressionism. This style of painting usually showed scenes of everyday life and nature, where the colours, shadows, and lights in the paintings are as real as possible, such as the paintings titled "The Cliff Walk Pourville", "The Japanese Footbridge", and "Haystacks." The exciting brush strokes and colours in Monet's paintings give you the feeling of being right there at the moment he made the painting.

Claude Monet lived to be 86 years old. He spent his last ten years painting scenes of his water garden, such as "Water Lilies." When Monet was older, people finally began to appreciate his now famous paintings. 